\title{
(6) OPEN ACCESS \\ Which extended paramedic skills are making an impact in emergency care and can be related to the UK paramedic system? A systematic review of the literature
}

\author{
Rachel Evans, ${ }^{1}$ Ruth McGovern, ${ }^{2}$ Jennifer Birch, ${ }^{2}$ Dorothy Newbury-Birch ${ }^{2}$
}

${ }^{1}$ Newcastle University Medical School, Newcastle Upon Tyne, UK

${ }^{2}$ Institute of Health and Society, Newcastle University, Newcastle Upon Tyne, UK

\section{Correspondence to} Dr Dorothy Newbury-Birch, Institute of Health and Society, Newcastle University, BaddileyClark Building, Richardson Road, Newcastle Upon Tyne NE2 4AX, UK;

dorothy.newbury-birch@ncl. ac.uk

Received 13 November 2012 Revised 21 February 2013 Accepted 24 February 2013 Published Online First 10 April 2013

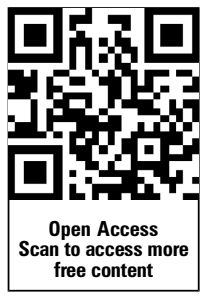

CrossMark

To cite: Evans $R_{\text {, }}$ McGovern R, Birch J, et al. Emerg Med J 2014:31: 594-603.

\begin{abstract}
Background Increasing demand on the UK emergency services is creating interest in reviewing the structure and content of ambulance services. Only 10\% of emergency calls have been seen to be lifethreatening and, thus, paramedics, as many patients' first contact with the health service, have the potential to use their skills to reduce the demand on Emergency Departments. This systematic literature review aimed to identify evidence of paramedics trained with extra skills and the impact of this on patient care and interrelating services such as General Practices or Emergency Departments.
\end{abstract}

Methods International literature from Medline, Embase, Cumulative Index of Nursing and Allied Health Literature (CINAHL), ProQuest, Scopus and grey literature from 1990 were included. Articles about any prehospital emergency care provider trained with extra skill(s) beyond their baseline competencies and evaluated in practice were included. Specific procedures for certain conditions and the extensively evaluated UK Emergency Care Practitioner role were excluded.

Results 8724 articles were identified, of which 19 met the inclusion criteria. 14 articles considered paramedic patient assessment and management skills, two articles considered paramedic safeguarding skills, two health education and learning sharing and one health information. There is valuable evidence for paramedic assessing and managing patients autonomously to reduce Emergency Department conveyance which is acceptable to patients and carers. Evidence for other paramedic skills is less robust, reflecting a difficulty with rigorous research in prehospital emergency care.

Conclusions This review identifies many viable extra skills for paramedics but the evidence is not strong enough to guide policy. The findings should be used to guide future research, particularly into paramedic care for elderly people.

\section{BACKGROUND}

Health services in many countries provide some sort of prehospital emergency response service for acute conditions based on the principle that prompt appropriate care can minimise the patient's mortality, morbidity and social consequences. ${ }^{1}{ }^{2}$ Paramedics perform this function in the UK, together with Emergency Care Assistants. Paramedics respond to emergency (999) calls and evaluate the patient, make necessary (sometimes life-saving) interventions and transfer the patient to hospital (non-transfers can only officially occur if the patient declines). They have a fundamental skill set $^{3}$ and can use a range of technical equipment and administer a limited list of medicines.

Population growth, epidemiological and demographic transition (the increasing burden of chronic disease and population ageing) and shortage of healthcare workers are affecting healthcare systems in many countries ${ }^{3}$ compelling them to adapt. For example, demand on UK ambulance services has increased steadily in the last 10 years but only $10 \%$ of calls are life-threatening. ${ }^{4}$

The UK government and health services recognise a need for adaptation to reduce these pressures on Emergency Departments (EDs). ${ }^{3}$ Ambulance service trusts have begun to respond to the recommendations made in 'Taking Healthcare to the Patient: Transforming NHS [National Health Service] Ambulance Services (2005)'. ${ }^{4}$ For example, new dispatcher decision-support software directly transferring between ambulance trusts and telephone health advice had increased the number of ambulance calls in the last 5 years. ${ }^{5}$ Table 1 details information from Canada, Australia, USA and France. Apart from France, the others have similar structures and problems to the UK.

Paramedics are many patients' first contact with the health service and thus have the potential to influence patients' care pathways. Currently, there is some evidence of allied health professionals with extended skills ${ }^{11}$ and paramedic skills for decision-making ${ }^{12}$ or treating minor ailments. ${ }^{13}$ One relevant systematic review described new roles in emergency medical services (EMS) with some cost-saving, ${ }^{14}$ but a paucity of studies with sufficient patient follow-up and consideration of training costs means that cost analyses are unreliable.

Service changes are not consistent across countries which risks disadvantaging patients or duplicating research. A systematic, unbiased collation of evidence of paramedics trained with extended skills is essential to ensure a sound evidence base to inform and justify developments to emergency services already strained by financial cuts. This systematic literature review aims to identify international evidence of circumstances in which prehospital emergency care providers-hereafter commonly referred to as 'paramedics'-have been trained with skills beyond their baseline competencies in new roles or within normal practice, and gauge the effectiveness of these skills in terms of patient care and service use. 
Table 1 International drivers of change and responses

\begin{tabular}{|c|c|c|c|}
\hline & Personnel and competencies & Problems & Responses \\
\hline UK & $\begin{array}{l}1 \text { paramedic per ambulance, work with Emergency Care } \\
\text { Assistants to provide emergency care and transportation }\end{array}$ & $\begin{array}{l}\text { Increasing and evolving types of } \\
\text { demands }\end{array}$ & $\begin{array}{l}\text { Regular updates of British Paramedic Association 'core } \\
\text { competencies' necessary for practice } \\
\text { Trials of 'Paramedic Practitioners' and introduction of } \\
\text { 'Emergency Care Practitioners' with extended skills }\end{array}$ \\
\hline Canada & $\begin{array}{l}4 \text { levels (Emergency Medical Responder up to Critical Care } \\
\text { Paramedic) with increasing competencies; exactly what, } \\
\text { varies between provinces }\end{array}$ & $\begin{array}{l}\text { Rural communities } \\
\text { Inter-provincial variation in training, } \\
\text { funding, skills, etc }\end{array}$ & $\begin{array}{l}2011 \text { National Occupancy Profiles (national) include } \\
\text { health promotion, patient safety }{ }^{6}\end{array}$ \\
\hline USA & $\begin{array}{l}4 \text { levels (Emergency Medical Responder up to Paramedic) } \\
\text { with increasing capabilities up to advanced life support }\end{array}$ & $\begin{array}{l}\text { Increased demand on public services } \\
\text { since introduction of Patient Protection } \\
\text { and Affordable Care Act } 2010\end{array}$ & $\begin{array}{l}1996 \text { Emergency Medical Services Agenda for Change: } \\
\text { integration with community services, acute and chronic } \\
\text { care, health monitoring } \\
2007 \text { National Scope of Practice Model standardising } \\
\text { care } \\
\text { 'Skilling up' Advance Emergency Medical Technicians } \\
\text { because cheaper than paramedics }\end{array}$ \\
\hline Australia & Titles, skills and responsibilities vary between provinces & $\begin{array}{l}\text { Rural communities } \\
\text { Difficulty recruiting-long hours, } \\
\text { problem maintaining skills, etc }\end{array}$ & $\begin{array}{l}\text { Queensland: role expansion and 'expanded scope' of } \\
\text { rural practitioners }{ }^{8} \\
\text { South Australia: 'multi-skilling' and partnership working } \\
\text { with other services. }{ }^{9} \text { The 'Rural Expanded Scope of } \\
\text { Practice' incorporated health education, screening and } \\
\text { minor injury treatment }{ }^{10}\end{array}$ \\
\hline France & $\begin{array}{l}4 \text { levels (Emergency Medical Technicians have } \\
\text { transportation vehicles up to Mobile Intensive Care Units } \\
\text { with high-tech equipment and an emergency doctor and } \\
\text { nurse on board) }\end{array}$ & \multicolumn{2}{|c|}{$\begin{array}{l}\text { French EMS prioritise providing the most appropriate patient management on scene, compared with } \\
\text { the swift transportation to hospital favoured in the UK. They have no paramedics but staff vehicles } \\
\text { with combinations of specially trained nurses and physicians }{ }^{6}\end{array}$} \\
\hline
\end{tabular}

EMS, emergency medical services.

\section{METHODS}

\section{Study design}

A comprehensive, sensitive search strategy was devised to include international, relevant studies. Any study design was eligible due to the relative lack of randomised controlled trials in prehospital emergency care. Search terms included the many different prehospital care provider titles used worldwide and synonyms for 'skill', 'extending roles' and 'impact'. Systematic reviews were considered for their intrinsic quality and the reviews' findings, not the findings of individual papers.

\section{Inclusion criteria}

Articles were included if they focused on paramedics trained with extra skills to perform tasks beyond their baseline competencies. 'Skills' pertains to specific capabilities in history taking, examination, diagnostics, and interventions or less tangible skills such as teamwork or decision-making. Skills may include partnership working with another service or be targeted at a patient group. Single skills acquired incrementally during normal training were excluded. Paramedics of different levels (eg, Paramedic Practitioners) were included, but other roles where skills used were not-comparable (eg, Emergency Care Practitioners (ECPs)) were not.

\section{Procedure}

Data sources included both peer-reviewed and non-peer-reviewed information sources: Medline, EMBASE, CINAHL, ProQuest, Scopus, Cochrane Database of Systematic Reviews, York Centre for Reviews and Dissemination, NHS Evidence, the Department of Health website, UK Public Health Observatory, British Library ( $\mathrm{PhD}$ theses), Web of Science (conference proceedings), Policy Network, Zetoc (conference proceedings) and Newcastle University Library index to theses. Additional papers were identified from reference lists or contacting authors of two or more or the final sample articles.
Databases were searched from 1990 onwards until the end of March 2012. This date was chosen to enable the identification of literature which may have influenced the attention on allied health professionals' skills in the 2000 UK NHS plan. ${ }^{15}$ No other filters were applied.

All resultant articles were sifted in two stages by two researchers, independently and blinded to one another's response. Quality assessment was performed using study design-appropriate Critical Appraisal Skills Programme (CASP) tools. ${ }^{16}$ A good/moderate/poor grade was allocated according to the quantity of positively marked CASP criteria. Grades were used not for exclusion but weighting of study findings. Data extraction forms using Microsoft Excel were piloted with three articles and amended accordingly. Quality assessment and data extraction were also performed by two independent and blinded researchers. Disagreements were resolved either by discussion or in consultation with another author.

\section{RESULTS}

A total of 8724 articles were identified during the search. Following removal of duplicates and sifting, the final sample for analysis contained 19 articles that met the inclusion criteria (figure 1).

In all, 19 articles described 15 original trials of varying methodology (tables 2-4).

Comparison of studies is problematic due to the wide variety of methodologies and paramedic skills focused upon. Studies are classified by the type of skill to the British Paramedic Association's core paramedic competences. ${ }^{17}$ Evidence was found for five of the nine categories.

\section{'Assessment and investigation of health' and 'planning/ preparation for and addressing of health requirements'}

These two categories are considered together because of the cross-over in skills. 


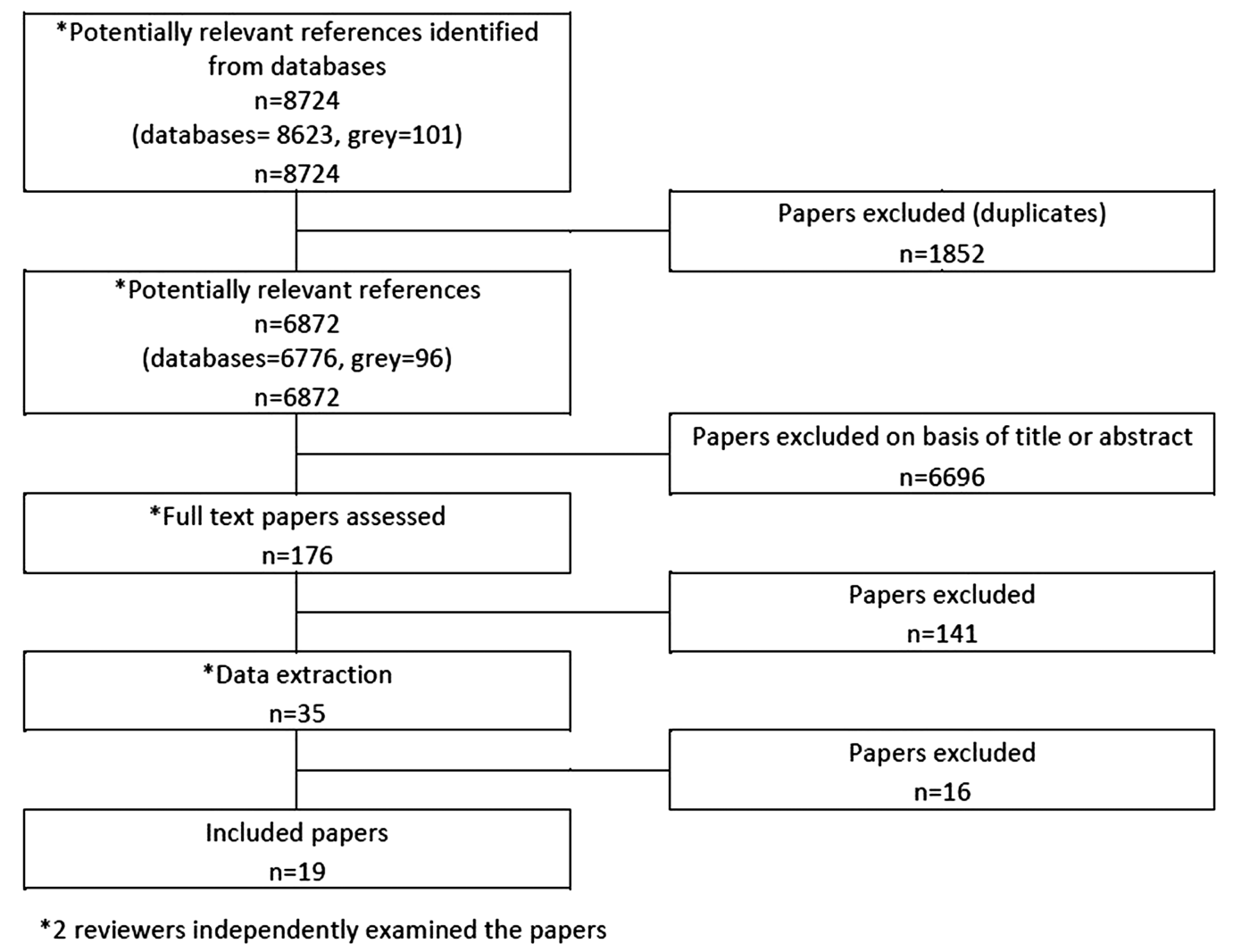

Figure 1 Preferred Reporting Items for Systematic Reviews and Meta-Analyses (PRISMA) statement of the progression of articles through the review.

Nine articles considered enhancing paramedics' normal EMS care skills relating to a variety of patient groups.

Paramedics in the UK can be trained with more sophisticated skills for assessing and managing patients aged over 60. ${ }^{1} 1819$ This is satisfactory to patients ${ }^{20}$ and carers ${ }^{1}$ but evidence for beneficial resource use difference compared with routine (control) care is lacking. ${ }^{18}$ Patients receiving care from trained paramedics are less likely to go to the ED or be admitted to hospital but had more secondary care contacts within 28 days. ${ }^{8} 18$ This may have been a result of more appropriate referrals, but jeopardises the safety of the model. There was no difference in mortality between intervention and control groups at 28 days and economic data were lacking. ${ }^{8}$ One single review article corroborated this benefit ${ }^{14}$ but their early searches miss the qualitative $^{1}$ and economic evaluation ${ }^{8}$ published later.

Evidence for skills focusing on other patient groups is weaker; for instance, paramedics trained with enhanced skills for managing children with special healthcare needs made more appropriate interventions compared with untrained paramedics. This may be due to the training being taken up by more motivated practitioners who may have performed better anyway. ${ }^{21}$ This intervention had no effect on resource use: the proportion of patients transported or admitted through the ED remained similar to pretraining levels. ${ }^{22}$ It is questionable why two articles on the same study used different comparison groups.

Paramedic training placements in UK general practices were acceptable to trainers and paramedics but not tested in practice. $^{23}$ They aimed to enhance the autonomy of normal EMS care. Paramedics working with UK General Practitioners (GPs) in a new 'appropriate care at point of need' (ACAPON) system were trained to treat minor injuries and make home visits alongside EMS care. ${ }^{24}$ 'Just under half' of treated patients remained in the community and others were admitted by 'the most appropriate pathway', generating an estimated saving of $£ 28279$ per annum (compared with routine GP and EMS care). Paramedics trained to assess and manage heat-injury patients at a mass event (450 000people) in urban Canada managed 126 patients who would have otherwise burdened another site care facility. ${ }^{25}$ Evaluations by the same author team of screening by paramedics initially focused on patients aged over $65^{26}$ but later those over $60^{27}$ which makes interpretation in relation to older patients difficult. We found that authors used different age cut-offs to identify patients as 'elderly'. Studies showed that paramedics could correctly identify the relevant features in patients, but they did not achieve sufficient coverage or follow-up intervention to constitute a 'screening programme'. ${ }^{28}$

\section{Development and sharing of information and knowledge of health}

Skills training described by Riley et $a l^{29}$ aimed to enhance Canadian paramedics' documentation of patients' ability to understand and decide (capacity) to decline ambulance transport showed no effect compared with pretraining records. It is important to ascertain if the $1.5 \mathrm{~h}$ of training did not work or was not enough.

\section{'Safeguard and protect individuals'}

Two safety studies in the USA showed that paramedics can accurately identify risks in homes, although not consistently and evidence of long-term benefit is lacking. ${ }^{30} 31$ Paramedics in one health department inspected 257 households for medication storage and 49 for gun storage (no reasons given), ${ }^{30}$ and paramedics from two ambulances tested carbon monoxide levels in 340 homes (out of up to 2637; not clear how many were indoors). ${ }^{31}$ 
Table 2 Study characteristics

\begin{tabular}{llll}
\hline Authors (year) (setting) & Aim of study & Methodology/quality & Participants \\
\hline
\end{tabular}

Assessment and investigation of health and planning/preparation for and addressing of health requirements

Cooper and Grant (2009) (international) To identify and describe the new roles Systematic review. Quality: moderate. High Inclusion criteria: articles reporting in out of hospital emergency care risk of selection bias, out of date significant development or change in

face-to-face ambulance, nurse or medical prehospital care practice published between 1998 and 2008. Exclusion criteria: non-English language article or 'minimal extensions' of practice

Dixon et al (2009) (UK urban)

Gerson et al (1992) (USA urban)

Knowles et al (2011) (UK urban)

Krumperman et al (1993) (USA urban)

Lukins et al (2004) (Canada urban)

Mason et al (2007) (UK urban)

Ruston and Tavabie (2011)

(UK not known)

Shah et al (2006) (USA rural)

Shah et al (2010) (USA rural)

Swain et al (2010) (New Zealand rural)

escribe a service to treat patients in their own communities, improve their experience and reduce conveyance to hospital

Planning/preparation for and addressing of health requirements (only)

Spaite et al (2001) (USA urban)

To improve EMS care, transport status or hospital admission of children with special healthcare needs

To assess the safety and cost-benefit of a Paramedic Practitioner (PP) elderly care model in EMS

To describe the role and training of a Primary Care Paramedic and a new urgent care system

To evaluate paramedics' ability to identify and refer elderly at risk

To understand impact of PP management of minor acute health episodes on carers

To give paramedics skills to recognise and intervene with social problems

To examine the feasibility of paramedic-staffed rehydration unit at mass gatherings

programme managing elderly patients with minor illness

To enhance paramedics' autonomous practice, knowledge and understanding of working in primary care

To evaluate the feasibility of EMS-based screening and health promotion promotion programme for the rural elderly
Economic evaluation of cluster RCT. Quality: moderate. Well-designed trial but substantial outcome data missing

escriptive report (case report) of educational and procedural change intervention. Quality: poor. High risk of bias and confounding, reporting lacks detail

Descriptive report (case report) of training and service change intervention. Quality: good. Low risk of bias

Cluster RCT of training and programme

change intervention. Quality: good.

Well-designed trial, low risk of bias.

Intention to treat analysis

Qualitative evaluation of pilot educational intervention. Quality: moderate. Inadequate detail about qualitative methodology

Quasi-experimental trial of training intervention, with control group. Quality: poor. High risk of bias

Quasi-experimental trial of education and service change intervention with control group. Quality: moderate. Moderate risk of bias, poor follow-up

Descriptive report (case report) of a training and service change intervention. Quality: moderate. Substantial risk of bias

Quasi-experimental study of educational intervention with control group. Quality: moderate. Small risk of bias and confounding and small influence of chance

Quasi-experimental study of educational intervention with control group. Quality:
7 experienced PPs were trained. Weeks were the unit of randomisation: 54 weeks randomised with or without a trained PP on duty. Control: in weeks with no PP on duty, patients receive EMS care as normal. Patient details passed to PP in ED and followed up 28 days later 1 community paramedic in 1 General Practice (GP). Control: not specifically, but evaluation compared with routine service

130 paramedics. No control

7 experienced PPs were trained. 54 weeks randomised with or without a trained PP on duty. Carers defined as 'provider of physical or emotional support to patient and present at time of episode'. Control: carers of eligible patients in control week (EMS care as normal)

Staff in 1 ambulance group-number of individuals not given. No control

12 paramedic team members per shift, 1-day event. No control

7 experienced PPs were trained. 54 weeks randomised with or without a trained PP on duty. Weeks with no PP on duty patients receive EMS care as normal. Patient details passed to PP in ED and followed up 28 days later

8 paramedic practitioner students. No control. Placements in accredited training practices

Staff in 1 ambulance service-number of individuals not given. Control: patients treated by comparable ambulance service EMS staff in 1 'health partnership' agency-number of individuals not given No control

Highest grade paramedics eligible for training (later, intermediate grades also accepted)—number of individuals not given. No control

All paramedics in district fire brigade: $68 \%$ uptake ( $n=52 / 89$ ). Control: 73/325 comparable pretraining responses

All paramedics in district fire brigade: $68 \%$ uptake $(n=52 / 89)$. Control: 53 
Table 2 Continued

\begin{tabular}{|c|c|c|c|}
\hline Authors (year) (setting) & Aim of study & Methodology/quality & Participants \\
\hline & $\begin{array}{l}\text { To determine effect of education } \\
\text { programme on EMS care, transport } \\
\text { status or hospital admission }\end{array}$ & $\begin{array}{l}\text { moderate. Risk of confounding and small } \\
\text { sample size (low uptake) }\end{array}$ & $\begin{array}{l}\text { eligible patients treated post-training by } \\
\text { untrained paramedics }\end{array}$ \\
\hline \multicolumn{4}{|c|}{ Development and sharing of information and knowledge of health } \\
\hline Riley et al (2004) (Canada urban) & $\begin{array}{l}\text { To determine whether an educational } \\
\text { intervention affected paramedic } \\
\text { documentation of patient } \\
\text { decision-making capacity }\end{array}$ & $\begin{array}{l}\text { Quasi-experimental study with control } \\
\text { group. Quality: poor. Appropriate design, } \\
\text { adequate follow-up but significant risk of } \\
\text { bias and confounding }\end{array}$ & $\begin{array}{l}200 \text { Emergency Medicine Technicians } \\
\text { (EMT) -Intermediates and EMT-Basics. } \\
\text { Control: } 698 \text { sample records taken } \\
\text { preintervention }\end{array}$ \\
\hline \multicolumn{4}{|l|}{ Safeguard and protect individuals } \\
\hline Hawkins et al (2007) (USA urban) & $\begin{array}{l}\text { To document paramedic assessment of } \\
\text { and intervention to mitigate } \\
\text { home-safety risks }\end{array}$ & $\begin{array}{l}\text { Quasi-experimental study of training and } \\
\text { service change intervention. Quality: poor. } \\
\text { High risk of bias }\end{array}$ & $\begin{array}{l}\text { Paramedics. } 77 \% \text { of } 262 \text { inspections } \\
\text { made by paramedics-number of } \\
\text { individuals not given. No control }\end{array}$ \\
\hline Jaslow et al (2000) (USA urban) & $\begin{array}{l}\text { To determine whether EMTs can } \\
\text { incorporate CO screening into } 911 \\
\text { responses and the cost-effectiveness }\end{array}$ & $\begin{array}{l}\text { Quasi-experimental study of training and } \\
\text { practice-change intervention. Quality: } \\
\text { poor. High risk of bias }\end{array}$ & $\begin{array}{l}2 \text { Basic Life Support (BLS) ambulances } \\
\text { were trained-number of individuals not } \\
\text { given. No control }\end{array}$ \\
\hline Willis et al (1997) (Australia rural) & $\begin{array}{l}\text { To create groups with the knowledge } \\
\text { and skills to support the community in } \\
\text { case of road trauma }\end{array}$ & $\begin{array}{l}\text { Descriptive report (case report) of group } \\
\text { building intervention. Quality: poor. } \\
\text { Strong influence of bias, lacks } \\
\text { generalisability }\end{array}$ & $\begin{array}{l}100 \text { people in } 6 \text { communities, including } \\
\text { 'some ambulance officers'. No control }\end{array}$ \\
\hline Stirling et al (2007) (Australia rural) & $\begin{array}{l}\text { To explore how 'community } \\
\text { engagement' aspects of paramedic } \\
\text { Extended Scope of Practice (ESP) } \\
\text { contribute to primary and emergency } \\
\text { healthcare }\end{array}$ & $\begin{array}{l}\text { Qualitative study with mixed data sources. } \\
\text { Quality: moderate. appropriate } \\
\text { methodology, poor reporting }\end{array}$ & $\begin{array}{l}\text { Up to } 17 \text { 'informants' at each of four } \\
\text { purposively sampled sites with ESP. No } \\
\text { control }\end{array}$ \\
\hline
\end{tabular}

CO, carbon monoxide; ED, Emergency Department; EMS, emergency medical services; RCT, randomised controlled trial.

This may result from families self-selecting for inspections ${ }^{30}$ or practical barriers in that paramedics took carbon monoxide measurements when clinical need allowed. ${ }^{31}$ This risks disadvantaging patients and limits the generalisability of the findings.

\section{Education and learning around health}

Two studies highlight a community engagement aspect to the paramedic role in rural Australia. Paramedics trained with skills to provide health education alongside patient management, screening, a 'first-point-of-contact' function, integration with voluntary services and increased community health capacity. ${ }^{32}$ Training paramedics alongside other individuals to increase community resilience to road trauma produced favourable results. ${ }^{33}$ 'Professionals' (mainly health workers, which would include paramedics, although the number is not clear) found practicing practical skills beneficial.

\section{Quality of this evidence and its meaning}

This review identified four 'good', ${ }^{19} 2534$ eight 'moder-

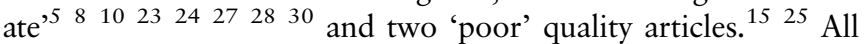
studies, except one, ${ }^{35}$ address a clearly focused question using an adequate, if not always ideal methodology. For example, although a randomised controlled trial could more rigorously evaluate the paramedic skill, controlling the patient group allocation is difficult and quasi-experimental design may be more appropriate.

The main weaknesses of the above studies are inadequate follow-up or accounting for patients not assessed by paramedics; a lack of controlling for confounding factors, such as patient characteristics or paramedics previous experience; and lack of control group or comparison data. These factors limit the reliability and attributability of outcomes.

\section{DISCUSSION}

There is some evidence from developed countries that paramedics can accurately identify health and social problems in patients and, in particular, those aged over $60 .^{5} 8111415182425$ Paramedics can be successfully trained to autonomously assess and manage these patients with acute minor conditions, benefitting patients, carers and (probably) resource use more widely. Evidence of costbenefit is however lacking. Evidence for paramedic care of other patient groups carries less weight but is valuable for informing future developments.

Paramedics working with enhanced skills are acceptable to service users and in the main reduced the burden on other care providers. Mason et al (2007) undertook the longest follow-up of 28 days, but longer follow-up may be required to assess the impact of extended paramedic care on patients' long-term health consequences. ${ }^{19}$ However, if services are aiming to reduce the burden on EDs, then this review corroborates that paramedics with extended skills may be a viable means for this, provided referral services have the capacity for the extra referrals from paramedics. Protocols for paramedics to 'treat and refer' have been trialled in the UK but have not altered the number of patients left at home, ${ }^{36}$ suggesting that protocolbased procedures are not sufficient and successful paramedic referrals need improved paramedic skills. Paramedic difficulty with destination decision-making has been highlighted in other studies: paramedics transport patients 'just in case' and rely more on intuition than formal decision-making procedures. ${ }^{36} 37$

There is no evidence for paramedics providing screening programmes, which must be comprehensive and provide accessible, effective interventions. ${ }^{28}$ This review suggests that paramedics can accurately but not comprehensively assess; evidence for the success of subsequent interventions is weak because it is based on case studies and inadequate sample sizes and follow-up. There is a risk to the safety of patients who screen positive (ie, are in need) and do not achieve contact with an appropriate service. Krumperman ${ }^{35}$ describes some potential barriers to paramedic referrals from the receiving services, including being already overburdened and a lack of resources or patient concordance with existing services. 
Table 3 Interventions and measures of included studies

\begin{tabular}{lll}
\hline Authors (year) Intervention Measures & M
\end{tabular}

Assessment and investigation of health and planning/preparation for and addressing of health requirements

Cooper and Grant (2009) NA

Dixon et al (2009)

Knowles et al (2011) PPs trained to provide community-based assessment, treatment and

PPs providing community-based assessment, treatment and referral of elderly patients with minor acute illnesses. Eligible patients aged $\geq 60$ presenting complaint within PP scope of practice, Sheffield postcode. Training method: 3-week full-time theory-based course with lectures from specialists in emergency medicine or elderly care and 45 days supervised clinical practice

Everden et al (2003) 'ACAPON' service: paramedic part of primary care team providing routine assessment, minor injury clinics and treatment, making home visits and liaising with doctors. Paramedic continues to respond to local emergency calls. Training method: 8-month placement but no detail about training given

Gerson et al (1992) Paramedics screen for and refer medical, mental health, social and environmental problems. Eligible patients aged $>60$ s. Training method: 4-h monthly sessions with presentations from specialists, with progress review every subsequent session referral of elderly patients with minor acute illnesses. Eligible patients aged $\geq 60$ with a Sheffield postcode. Training method: 3-week full-time theory-based course with lectures from specialists and 45 days supervised clinical practice

Krumperman et al (1993) Paramedics identify individuals 'at-risk' and make referrals. Training method: teaching by volunteer staff to recognise risk factors for child abuse, sexual abuse, isolation, mental illness and those specific to elderly

Lukins et al (2004) Paramedics screen, assess and intervene for heat-related injury in a purpose-built venue. Aiming to assess, treat and discharge in $<120$ min. Training method: 20 min session before shift started, written and verbal information about features and management of dehydration

Mason et al (2007) PPs providing community-based clinical assessment, treatment and referral of elderly patients with minor acute illness. Eligible patients aged $\geq 60$, presenting complaint within PP scope of practice, Sheffield postcode. Training method: 3-week full-time theory-based course with lectures from specialists in emergency medicine or elderly care and 45 days supervised clinical practices

Ruston and Tavabie (2011) (Pilot) education placements in General Practices. Training method: 2-month apprenticeship-type placement and one shorter 'sign-off' placement. Workplace-based teaching includes patient assessment, differential diagnosis, clinical management plans, consultation skills and teamwork

Shah et al (2006) EMS practitioners screened patients aged $>65$ for vaccine status and falls risk. Distributed educational documents and referred to GP if necessary. Eligible patients aged $>65$. Training methods: $90 \mathrm{~min}$ case-based discussion, instruction how to ask screening questions. Training 'reinforced' monthly

Shah et al (2010) Paramedics screened patients aged $>60$ in the community for falls depression and medication management strategies. Offer Case Manager if appropriate. Eligible patients aged $>60$. Training method: Geriatric Education for EMS course including communication and assessment, abuse and neglect, emergencies, mental health. 1 day for BLS professionals, 1.5 day for Advanced Life Support

Swain et al (2010) Extended care paramedics sent to eligible patients (emergency calls triaged as suitable) and can clinically assess, refer to GPs of community health staff, use range of medication at patient's home, transfer to appropriate facility or revisit later to enhance care. Service operates $12 \mathrm{~h} /$ day, 7 days/week. Training method: 1 month's additional training from experienced staff and regular training days and service audits

Planning/preparation for and addressing of health requirements (only)

Spaite et al (2001) Paramedics manage patients aged $<21$ years with physical or mental condition affecting growth and development, requiring: 'an assistive technology device; prolonged or frequent hospitalisation; a specialised approach to assessment or management'. Training method: self-study programme containing information about most common conditions including a manual, a video, practice manikins, quizzes and observed skills evaluations

\section{NA}

Routine clinical data (to estimate resource use), EQ-5DTM questionnaire to calculate Quality Adjusted Life Years (QALY). Cost of $\mathrm{PPs}$, alternative responders and ED/social/community/inpatient care. £20 000/QALY threshold

Treatments in the community, appropriate hospital admission pathways, ambulance usage, care costs

'Usefulness' of referral defined as a real problem amenable to intervention and help consequently received, or 'usefulness' to caregiver. 'Real' problem validated by geriatrician

Intervention and control carers sent questionnaire at 7 days about satisfaction and change in care burden. Reminder sent at 14 days

'Accuracy' of referral (no definition given)

Recorded outcomes were opening times, patient numbers, patient complaints, admission and discharge times and patient outcome

ED attendance, hospital admission (0-28 days), interval from call time to discharge (episode time), patient satisfaction, investigation and treatment, health status and mortality at 28 days. Data from hospital and ambulance records and patient questionnaire at 28 days

Placement acceptability, support received and how many patients assessed. Identification and address of learning needs. Fulfilment of specific competencies: communication, consultation, holistic care, data gathering and interpretation. Review of placement structure. Online survey and interviews (trainees and trainers)

Screening 'successful' if status confirmed by primary care provider. Telephone survey at 2 weeks for 'effect' of intervention: vaccine uptake, recollection of education information

'Successful evaluation' of unmet need=completed questionnaire. Patient satisfaction survey and completion of home visit. Follow-up at 2 weeks

Transfers to hospital, type and characteristic of patient, presenting problem, route of access, proportion of EMS workload 
Table 3 Continued

\begin{tabular}{|c|c|c|}
\hline Authors (year) & Intervention & Measures \\
\hline Spaite et al (2001) & $\begin{array}{l}\text { Paramedics with improved skills and knowledge to treat children with } \\
\text { special healthcare needs (requiring: 'an assistive technology device; } \\
\text { prolonged or frequent hospitalisation; a specialised approach to } \\
\text { assessment or management') Training method: self-study programme } \\
\text { containing information about common conditions including a manual, } \\
\text { a video, practice manikins, quizzes and observed skills evaluations }\end{array}$ & $\begin{array}{l}\text { Patient characteristics, diagnosis, level of care received, procedures } \\
\text { performed, destination (type of facility), discharge status }\end{array}$ \\
\hline \multicolumn{3}{|c|}{ Development and sharing of information and knowledge of health } \\
\hline Riley et al (2004) & $\begin{array}{l}\text { EMTs improving documentation of patient decision-making capacity for } \\
\text { transport refusal. All EMS patients eligible. Training method: } 1.5 \mathrm{~h} \\
\text { module with case-based small group discussion led by physician. } \\
\text { Includes importance and procedure of assessment and documentation }\end{array}$ & $\begin{array}{l}\text { Reviewed convenience sample of ambulance call records (ACRs, } \\
\mathrm{N}=75 \text { ) from each group. Reviewed for presence of signature and } \\
\text { capacity assessment procedure. Accuracy assessed by re-entry of } \\
\text { ambulance call records data by blinded reviewer, sample } \mathrm{N}=15\end{array}$ \\
\hline \multicolumn{3}{|c|}{ Safeguard and protect individuals } \\
\hline Hawkins et al (2007) & $\begin{array}{l}\text { Paramedics undertaking paediatric home safety assessment and } \\
\text { providing safety devices and advice. Families with children or expectant } \\
\text { mothers were eligible and invited by mail to request visit. Training } \\
\text { method: } 1 \text { day about injury, how to conduct safety inspections, use } \\
\text { injury prevention survey and mitigate injury risk. Catch-up sessions for } \\
\text { late entering paramedics }\end{array}$ & $\begin{array}{l}\text { Paper survey measured: average visit time length, directly observed } \\
\text { safety hazards, functioning safety devices, evacuation plans, } \\
\text { hazardous practices, hazard mitigation by paramedics }\end{array}$ \\
\hline Jaslow et al (2000) & $\begin{array}{l}\text { EMTs to take CO measurements. Positive readings referred to fire } \\
\text { department. Calls not requiring advanced life support management } \\
\text { were eligible. Training method: } 2 \mathrm{~h} \text { inservice training session about } \\
\text { signs/symptoms and causes of CO poisoning, use of metres and } \\
\text { administration of questionnaire }\end{array}$ & $\begin{array}{l}\text { Positive reading confirmed by fire department, detector present in } \\
\text { home, patient knowledge about CO poisoning }\end{array}$ \\
\hline Willis et al (1997) & $\begin{array}{l}\text { Community groups created to improve road trauma management, local } \\
\text { support and community networking. Rural communities eligible. } \\
\text { Training method: four free facilitator-led sessional workshops (role play, } \\
\text { group exercises, discussions) including knowledge about grief and } \\
\text { coping awareness, disaster planning, community resources and referral } \\
\text { pathways }\end{array}$ & $\begin{array}{l}\text { Impact: (questionnaire): 'most useful' session, skills, knowledge and } \\
\text { personal coping strategies gained. Outcome: (opportunistic focus } \\
\text { group postroad trauma): application of knowledge, coping strategies, } \\
\text { knowledge and application of support services }\end{array}$ \\
\hline Stirling et al (2007) & $\begin{array}{l}\text { Paramedics with ESP can enhance communities through health } \\
\text { promotion, capacity building and community development. Training } \\
\text { method: not clear, may vary between sites }\end{array}$ & $\begin{array}{l}\text { Interviews with 'key informants', observations of 'key processes and } \\
\text { events' and 'review of documents that describe the paramedic role, } \\
\text { available organisational and educational support' }\end{array}$ \\
\hline
\end{tabular}

ACAPON, appropriate care at point of need; CO, carbon monoxide; ED, Emergency Department; EMS, emergency medical services; ESP, Extended Scope of Practice; GP, General Practitioner; PP, Paramedic Practitioner.

Paramedics may have a valuable role in rural community health capacity and health promotion (including, interestingly, first aid teaching) but this requires further investigation to identify the exact characteristics and benefits of such roles. Evidence for home safety roles was inadequate. All paramedic skill changes required some sort of support from the wider ambulance service, such as call-handling and engagement with trainers and patients. There may be person factors limiting the success of paramedic skill extensions in some circumstances, which have not been explored in this review.

There is no conclusive evidence to recommend one training method over another in this review. Most studies incorporated a combination of theory and practical training which reflects current UK paramedic training, but a vast range of methods were identified. Even similar methods were not similarly effective; a 90 min case-based discussion did not change practice ${ }^{29}$ but a 90 min case-based 'instruction' resulted in accurate screening but no effect on vaccine rates. ${ }^{25}$

Everden et $a l^{24}$ note that although 'some GPs may be wary of something which appears to give them more work', paramedics may be effectively trained in primary care; many GPs already have training qualifications and are familiar with the assessments and clinic experience fosters autonomous practice. ${ }^{23}$ The development of confident autonomous practice is essential if paramedics are to make referrals or decide to leave patients at home, as has been shown to be effective. ${ }^{20}$ The experiential learning may help paramedics to rely less upon protocols and hospital transfer as fall-back options.
Claims of cost-effectiveness were based on missing data, ${ }^{24}$ were not statistically significant ${ }^{8}$ or subject to outcome bias. For example, Paramedic Practitioners were $£ 92$ less costly if the equivalent care is fast-response vehicle staffed by ECPs, ${ }^{18}$ which is credible because ECPs also undertake extensive training. However, were the comparison group relatively less-skilled Emergency Medical Technicians, the saving would be substantially less, if any. ACAPON saves an estimated annual $£ 28729,{ }^{24}$ but this may be susceptible to case study outcome bias. ${ }^{38}$

Although no system of grading by quality currently exists, the use of validated measures from the CASP tools made this review's crude grades objective and reliable. It was also sensitive enough to identify differences in quality within the same study design.

\section{RECOMMENDATIONS}

Further research is required in order to develop some of the findings of this review. These may differ between geographical regions, as different communities have distinct needs. Suggestions for the UK include:

A. An EMS trial register is reinstated to improve the accessibility, quality and quantity of emergency research.

B. A centralised database for ambulance and emergency patient data and a common reporting template for research and innovation ${ }^{39}$ is designed and shared to improve the quality and accessibility of informal research ('grey' literature). 
Table 4 Findings from studies

Authors (year) Findings

Assessment and investigation of health and planning/preparation for and addressing of health requirements

Cooper and Grant (2009) Results: 48 articles in total, and two (RCT and qualitative) describe the Paramedic Practitioner (PP). 1 paper (qualitative) refers to partnership working between paramedics and nurses. PPs are paramedics with 'graduate level skills' operating in normal ambulance service conditions and in one trial were given a 3-week course and 45 days supervised practice for advanced health assessment and skills for an elderly population. Findings about ECPs beyond scope of this review. PPs' patients were less likely to attend ED after initial episode, more satisfied than control groups and experienced shorter episode times. They were more likely to use secondary services. Partnership service was perceived to increase confidence and improve care

Dixon et al (2009) 3081 consenting patient encounters. Response rate $34 \%-43 \%$. Significant differences in resource use ( $p<0.05)$. Intervention groups: longer on scene time, more secondary care contacts within 28 days and more hospital time. Control group patients: more likely to go to the ED, be admitted to hospital and spend longer in ED or hospital. Similar patterns of primary and community care use in 28 days following. Overall $\mathrm{PP}$ costs $\mathrm{f} 73$ (95\% Cl 70 to 76$)$, other responder $€ 77$ (95\% Cl 68 to 78$)$. Overall PP $£ 140$ less but not statistically significant. $72.7 \%-73.7 \%$ data missing. PPs $\mathrm{f680}$ less costly, 0.0003 fewer Quality Adjusted Life Years, PP >95\% chance of being cost-effective

Everden et al (2003) $\quad 305$ patients seen by ACAPON paramedic. 11 hospitalised, 5 transferred to ED. 125 Category A calls received. Of calls processed by ACAPON, 'just under half' remained in community, others admitted by 'most appropriate pathway'. 'Over half' back-up ambulances were downgraded red-urgent or stood down completely. Number of calls responded to within time limit $55 \%-85 \%$. Estimated total cost saving £28 729 per annum

Gerson et al (1992) Paramedics assessed 197 patients: $37 \%$ had one problem, $31 \%$ two, $18 \%$ three, $13 \%$ four. Only $63 \%$ were subsequently assessed by geriatrician ( $11 \%$ refused). Paramedics screening had $98 \%$ positive predictive value. Programme 'useful' in $50 \%$ of cases and equal benefit to all problem types

Knowles et al (2011) 569 eligible carers. $71.5 \%$ response rate ( $\mathrm{n}=401 / 561$ carers). Care-recipient characteristics 'similar' between groups. Carers predominantly female, aged $\sim 60$, family members and $75 \%$ provide 'some form of care' before episode. Intervention group carers were more likely to be family members, to be satisfied with their care, express a preference for care to be delivered at home and report less of an increased care burden postepisode

Krumperman et al (1993) During the 19 months the trial ran, 50 referrals were made. Unknown how many patients seen. A high proportion of referrals were made for elderly patients: issues of abuse, isolation, loneliness and lack of services were identified

Lukins et al (2004) 143/450 000 attendees treated, 126 who would have been treated in main field hospital. 463 patients ineligible because non-heat related injury. Chief complaints: syncope, presyncope, dizziness. $75 \%$ patients discharged, $12 \%$ moved to main field hospital, $1 \%$ hospital off-site. $23 \%$ length of stay $>120$ min but did not need transfer (mean=94 min, missing $n=25$ ). Unit was safe and successful

Mason et al (2007) 3018 patients consented out of 4175 eligible. $65 \%$ questionnaire response rate. Intervention patients $n=1549$ (1090 received intended PP response), control $n=1469$ (adequate power). No difference in baseline patient demographics but carers $72.6 \%$ women, average age 82.6 . Intervention patients were less likely to attend ED or be admitted and more likely to have shorter episode time and be highly satisfied. No difference in 28-day mortality

Ruston and Tavabie (2011) 8 paramedic trainees and 8 GP trainers participated and responded. All responses were positive regarding acquisition of skills, knowledge and understanding to work effectively in GP and avoid hospital admissions. High quality learning experience and enabled students to put skills into practice

Shah et al (2006) 669 patients were eligible and participated in intervention group, 272 in control group. Comparable characteristics. Screening 'successful' for pneumococcal vaccine status $(79 \%)$, influenza vaccine $(76 \%)$, falls history $(91 \%)$, environmental hazards ( $87 \%)$. Statistically significantly greater pneumococcal vaccine rates in intervention group but no change in influenza vaccine or falls prevention measures. Paramedics could successfully identify those at risk but did not alter these proportions

Shah et al (2010) 1231/1444 eligible patients screened. Of those screened, $33 \%(n=240 / 728)$ positive for depression, $68 \%$ ( $n=552 / 814)$ at risk of falling, $90 \%$ (852/950) at risk for medication management problems. $73 \%$ refused further intervention. Case Manager intervention: 635 were offered home visit, 171 accepted, 153 completed, 130 followed up (at 2 weeks). 92\% of these were satisfied with whole programme. 130 patients were followed up. 583 patients attended by extended care paramedics, $25 \%-30 \%$ EMS workload. 38\% transported to hospital. $49 \%$ patients aged $>75.78 \%$ medical condition, $22 \%$ traumatic

583 patients attended by extended care paramedics, 25\%-30\% EMS workload. 38\% transported to hospital. 49\% patients aged $>75$. $78 \%$ medical condition, $22 \%$ traumatic

Planning/preparation for and addressing of health requirements (only)

Spaite et al (2001) N N $\quad \mathrm{N} 332$ eligible calls, random sample of 74 reviewed. Overall appropriateness of paramedic care was significantly better for paramedics in trained group than non-trained $(x 2=6.33, p=0.01)$. Specific improvements were in initial and disability assessments. No significant difference in 'appropriate' review between professional groups

Development and sharing of information and knowledge of health

Riley et al (2004) $\quad \mathrm{N}=150$ patients records reviewed at 1 month, $\mathrm{N}=504$ measured at 12 months. Following the educational module: no difference in frequency of documentation, fewer refusals. Increase in total patient transports. Accuracy rate of documentation was $92.6 \%$

Safeguard and protect individuals

Hawkins et al (2007) $\quad 262$ inspections were made. Large proportion of households lacking safety devices or with hazardous practices. Between $25 \%$ and $100 \%$ received missing devices through programme. Paramedics can recognise common hazards and provide mitigating tools. No follow-up took place to measure impact on child safety

Jaslow et al (2000) Responded to 2637 EMS calls in 2 months. 340 readings taken: nine were positive, one source and 0 life-threatening levels were found. 212 surveys completed, $68 \%$ heard of CO poisoning, $37 \%$ could name symptoms. No information about cases in which readings were not taken; therefore, no conclusions can be drawn

Willis et al (1997) $\quad 62 \%$ response rate to questionnaire ( $\mathrm{N}=65)$. 'Building community networks' was most useful (66\%), $85.7 \%$ increased their knowledge of community networks, $87 \%$ responded positively about increasing skills for responding to road trauma. All had increased understanding of many aspects and felt workshops had increased the ability to cope with road trauma. Professionals felt that they had not gained new skills but refreshed existing ones 
Table 4 Continued

\begin{tabular}{ll}
\hline Authors (year) & Findings \\
\hline Stirling et al (2007) & $\begin{array}{l}\text { Paramedic ESPs promote rural community health by increasing community response capacity, linking communities closely to ambulance } \\
\text { services and undertaking health promotion and illness prevention work. Communities report increased awareness and improved volunteer } \\
\text { services (eg, following community first aid training) }\end{array}$ \\
\hline
\end{tabular}

ACAPON, appropriate care at point of need; CO, carbon monoxide; ECP, Emergency Care Practitioners; ED, Emergency Department; EMS, emergency medical services; ESP, Extended

Scope of Practice; GP, General Practitioner; RCT, randomised controlled trial.

C. Future adaptations to emergency care to address current pressures adopt a systems perspective in order to comprehensively assess the impact on all the relevant actors. Evidence for changes must include qualitative, quantitative and economic evaluations to ensure the quality and reproducibility of research.

This review identified the interaction of paramedics with other community services as the most promising means of reducing demand on EDs. Therefore, further investigation is needed in these areas:

A. Paramedics working with GPs. This has the potential to save costs and resources and is beneficial and acceptable to paramedics and GPs. ${ }^{23}{ }^{24}$ Specifically, 'ACAPON' should be trialled further in the UK.

B. Paramedic referrals to non-EDs. Specifically, which patients and conditions benefit from paramedic referrals and which require hospital management and the current barriers to paramedic referral.

C. Paramedics assessing and managing acute minor conditions in elderly patients. There is the strongest evidence base for this skill development. Good practice models, such as that by Mason et al (2007), ${ }^{19}$ should be taken up where trusts have the capacity to train a paramedic and these outcomes should be tightly monitored and shared.

In order to develop the features identified in this review, it is essential to ascertain which patients and conditions are suitable for autonomous paramedic care in order to protect patient safety. Where paramedic referral schemes already exist, barriers to their success should be investigated, including how many referral services are actually available for the demand. Furthermore, to facilitate the translation of such research, a systems perspective should be employed to identify the wider logistical, financial and other implications of changes to ambulance services; for example, extra training or capacity required for call-handlers to improve the appropriateness, acceptability and success of paramedic skill innovations.

\section{LIMITATIONS}

Identified articles used assorted methodologies and focused on varied skills and patient groups, meaning meta-analyses could not be performed and therefore deductions are only based on narrative syntheses. It is also important to note that qualifications may differ across different countries and that for instance an ECP in one country may have different roles in another and this could have affected the findings. Finally, it could be that a one-sided focus on adapting services to increasing demand ignores patients' responsibility to access the correct service.

\section{CONCLUSIONS}

This review identifies many viable extra skills for paramedics but the evidence is not strong enough to guide policy. Instead, its findings should be used to guide future research, particularly into paramedic care for elderly people.
Acknowledgements James Petter, College of Paramedics, UK and Dahrlene Tough, Scottish Ambulance Service, UK.

Contributors RE, DNB and RM were involved in the design of the research. $\mathrm{RE}$ and JB carried out the systematic review under the supervision of DNB and RM. RE drafted the article with all authors contributing to the writing of the article.

Collaborators None.

Funding None.

Disclaimer None.

Competing interests None.

Provenance and peer review Not commissioned; externally peer reviewed. Data sharing statement Not obtained.

Open Access This is an Open Access article distributed in accordance with the Creative Commons Attribution Non Commercial (CC BY-NC 3.0) license, which permits others to distribute, remix, adapt, build upon this work non-commercially, and license their derivative works on different terms, provided the original work is properly cited and the use is non-commercial. See: http://creativecommons.org/ licenses/by-nc/3.0/

\section{REFERENCES}

1 Knowles $E$, Mason S, Colwell B. An initiative to provide emergency healthcare for older people in the community: the impact on carers. Emerg Med J 2011;28:316-19.

2 World Health Organization. Geneva: Prehospital trauma care systems, 2007. Available online at http://www.who.int/violence_injury_prevention/publications/ services/39162_oms_new.pdf

3 The Ambulance Service Network. A vision for emergency and urgent care: the role of the ambulance services. London: The NHS Confederation, 2008.

4 Department of Health. Taking healthcare to the patient, transforming NHS ambulance services. London, 2005.

5 Association of Ambulance Chief Exectutives. Taking healthcare to the patient 2: a review of 6 year's progress and recommendations for the future. England, 2011.

6 Adnet F, Lapostolle F. International EMS systems: France. Resuscitation 2004;63:7-9.

7 National Highway Traffic Safety Administration. National EMS Scope of Practice model. 2007.

8 Raven S, Tippett V, Fergison J, et al. An exploration of expanded paramedic healthcare froles for Queesland. Australia: Australian Centre for Prehospital Research, 2006.

9 South Australia Ambulance Service. Defining the road ahead: service delivery model 2008-2015. South Australia: Government of South Australia, 2007.

10 O'Meara P. The rural and regional ambulance: moving beyond emergency response. Albury NSW 9th National Rural Health Conference 7-10 March Standing Up for Rural Health: Learning from the Past, Action from the Future Program \& Papers; Albury, New South Wales: National Rural Health Alliance, 2007:1-8.

11 McPherson K, Kersten P, George SM, et al. A systematic review of evidence about extended roles for allied health professionals. J Health Serv Res Policy 2006;11:240-7.

12 Driscoll P, Kent A. The effect of scene time on survival. Trauma 1999;1:23-30.

13 Ball L. Setting the scene for the paramedic in primary care: a review of the literature. Emerg Med J 2005;22:896-900.

14 Cooper SJ, Grant J. New and emerging roles in out of hospital emergency care: a review of the international literature. Int Emerg Nurs 2009;17:90-8.

15 Department of Health. The NHS Plan: A plan for investment, a plan for reform. London: HMSO Copyright, 2000.

16 Critical Appraisal Skills Programme. Find-Appraise-Act. 2011 [28/11/2011].

17 British Paramedic Association. Curriculm guidance and competence framework. UK, 2008.

18 Dixon $S$, Mason $S$, Knowles $E$, et al. Is it cost effective to introduce paramedic practitioners for older people to the ambulance service? Results of a cluster randomised controlled trial. Emerg Med J 2009;26:446-51.

19 Mason S, Knowles E, Colwell B, et al. Effectiveness of paramedic practitioners in attending 999 calls from elderly people in the community: cluster randomised controlled trial. BMJ 2007:335:919-22. 
20 Mason S, Knowles E, Colwell B, et al. Effectiveness of paramedic practitioners in attending 999 calls from elderly people in the community: cluster randomised controlled trial: BMJ 2007;335:919-922.

21 Spaite DW, Karriker KJ, Conroy C, et al. Emergency medical services assessment and treatment of children with special health care needs before and after specialized paramedic training. Prehosp Disaster Med 2001;16:96-101.

22 Spaite DW, Conroy C, Karriker KJ, et al. Improving Emergency Medical services for children with special health care needs: does training make a difference? Am J Emerg Med 2001;19:474-8.

23 Ruston AA, Tavabie AA. An evaluation of a training placement in general practice for paramedic practitioner students: improving patient-centred care through greater interprofessional understanding and supporting the development of autonomous practitioners. Qual Prim Care 2011;19:167-73.

24 Everden $\mathrm{P}$, Eardley M, Lorgelly $\mathrm{P}$, et al. Emergency care. Change of pace. Health Serv J 2003;113:28-30.

25 Lukins JL, Feldman MJ, Summers JA, et al. A paramedic-staffed medical rehydration unit at a mass gathering: Prehosp Emerg Care 2004;8:411-16.

26 Shah M, Clarkson L, Lerner $E$, et al. An emergency medical services program topromote the health of older adults. J Am Geriatr Soc 2006;54:956-62.

27 Shah M, Caprio T, Swanson P, et al. A novel emergency medical services program to promote the health of older adults. J Am Geriatr Soc 2010;58:2205-11.

28 National Screening Committee. What is screening? UK screening. UK2012 [22/08/ 2012].

29 Riley J, Burgess R, Schwartz B. Evaluating the impact of an educational intervention on documentation of decision-making capacity in an emergency medical services system. Acad Emerg Med 2004;11:790-3.
30 Hawkins ER, Brice JH, Overby BA. Welcome to the world: findings from an emergency medical services pediatric injury prevention program. Pediatr Emerg Care 2007:23:790-5.

31 Jaslow D, Ufberg J, Ukasik J, et al. Routine carbon monoxide screening by emergency medical technicians. Acad Emerg Med 2001;8:288-91.

32 Stirling CMCM, O'Meara PP, Pedler DD, et al. Engaging rural communities in health care through a paramedic expanded scope of practice. Rural Remote Health 2007;7:839.

33 Willis $K$, Cameron P, Igoe P. Building community networks: a road trauma education and training program for rural areas. Aust J Rural Health 1997:5:6-10.

34 Gerson LW, Schelble DT, Wilson JE. Using paramedics to identify at-risk elderly. Ann Emerg Med 1992;21:688-91.

35 Krumperman KMK. Filling the gap. EMS social service referrals. JEMS 1993:18:25-9.

36 Snooks H, Kearsley N, Dale J, et al. Towards primary care for non-serious 999 callers: reults of a controlled study of "Treat and Refer" protocols for ambulance crews. Qual Saf Health Care 2004;13:435-43.

37 Halter M, Vernon S, Snooks $\mathrm{H}$, et al. Complexity of the decision-making process of ambulance staff for assessment and referral of older people who have fallen: a qualitative study. Emerg Med J 2011;28:44-50.

38 Oliveira G, Leles C. Critical appraisal and positive outcome bias in case reports published in Brazilian dental journals. Int Dent Educ 2006;70:869-74.

39 Commission for Healthcare Audit and Inspection. Not just a matter of time. A review of urgent and emergency care services in England. London: Healthcare Commission, 2008. 